\title{
A Case of Giant Hairy Pigmented Nevus of Face
}

\author{
Col Virendra Bhatnagar*, Col MK Mukherjee, YsM $^{+}$, Brig Pradeep Bhargava ${ }^{\#}$
}

MJAFI 2005; $61: 200-202$

Key Words : Congenital nevus; Giant hairy nevus; Malignant melanoma

\section{Introduction}

$\mathrm{G}$ iant hairy nevus of the face is a unique form of congenital nevus, fortunately rare and typically hairbearing. In its usual form, it is large and disfiguring, thus the name garment or bathing trunk nevus. These lesions have a relatively high risk of becoming malignant. These lesions, when large, make a formidable undertaking in view of lack of suitable donor sites and multiple procedures involved in its treatment. Giant hairy nevus of the face is a particular challenge to a plastic surgeon not only because of a very high standard of skill required but also for the patient and parental concern for cosmetic results. This paper presents as to how the different modalities of treatment were applied to achieve good cosmetic results.

\section{Case Report}

A 9 year old boy, subject of Nepal presented to the OPD of a reconstructive surgery center with a giant pigmented hairy nevus of the face. The lesion involved the right zygomatic region, right cheek; right upper and lower eyelids, right eyebrow and whole of the nose even extending on to the left infraorbital region (Fig. 1). The lesion measured 12 $\mathrm{cms}$ X $8 \mathrm{cms}$ in size. The child was a victim of ridicule at school and was brought for management of this major cosmetic defect by his parents. The child was planned for staged surgical management. In $1^{\text {st }}$ stage the lesion over the right upper eyelid was excised preserving a margin of $1 \mathrm{~mm}$ at the lid margin and the skin cover was provided by a full-thickness skin graft obtained from left retro auricular region. The graft donor site was closed primarily. In the same sitting, the lesion involving the right zygomatic, infraorbital region and cheek was also excised and replaced by full-thickness skin graft harvested from left groin from the non-hair bearing area. The donor site was closed primarily. The donor sites healed well with little donor site deformity. The graft take over the recipient site was $100 \%$ with excellent colour match. The $2^{\text {nd }}$ stage reconstruction was undertaken 6 months later. This involved the management of total nasal skin. To achieve this, the technique of tissue expansion was used. A tissue expander of $300 \mathrm{ml}$ was inserted in the forehead and gradually expanded over a period of 6 weeks. Later, this expanded forehead skin was utilized for a forehead flap to replace the entire lesion involving the nose and left infraorbital region. The flap donor site was closed primarily with no donor site deformity. The flap settled well and was detached and finally inset after 3 weeks. The results were excellent cosmetically. The forehead flap donor site scar was barely visible after 3 months (Fig 2).

\section{Discussion}

Congenital pigmented nevi are present in approximately 2 to $3 \%$ of neonates. Fewer than $10 \%$ of these lesions are larger than 3 or $4 \mathrm{cms}$, a size cut-off below which the designation small is usually given. Large and giant are debatable and confusing terms. A review of literature found that the definition of 'giant' was variable. Pers [1] had defined 'giant' as palm size on the face and twice palm size elsewhere. While some authors felt that an area of more than 144 square inches was 'giant' [2], others considered a lesion that could not be completely excised and closed primarily as 'giant' [3].

It is now well established that giant congenital nevi and malignant melanoma are associated, despite the fact that the magnitude of risk of malignant transformation is still the subject of wide controversy. Widely divergent figures range from $1.8 \%$ to up to $45 \%$. A recent review [4] on the subject have calculated an $8.52 \%$ incidence of melanoma developing within nevi larger than $2 \%$ of the total body surface during the first 15 years of life.

Despite the controversy, many clinicians agree that prophylactic excision of all giant and large hairy nevi is indicated [5]. The opinion regarding complete prophylactic excision of all giant nevi should be accomplished in infancy and early childhood is well supported in literature [6] by the evidence that $60 \%$ of the malignancies developing in these lesions present in

*Senior Adviser (Surgery and Reconstructive Surgery), Command Hospital (Central Command), Lucknow, ${ }^{+}$Senior Adviser (Surgery \& Reconstructive Surgery), "Consultant (Surgery \& Reconstructive Surgery), Army Hospital (R\&R), Delhi Cantt.

Received : 16.01.2002; Accepted : 23.09.2004 


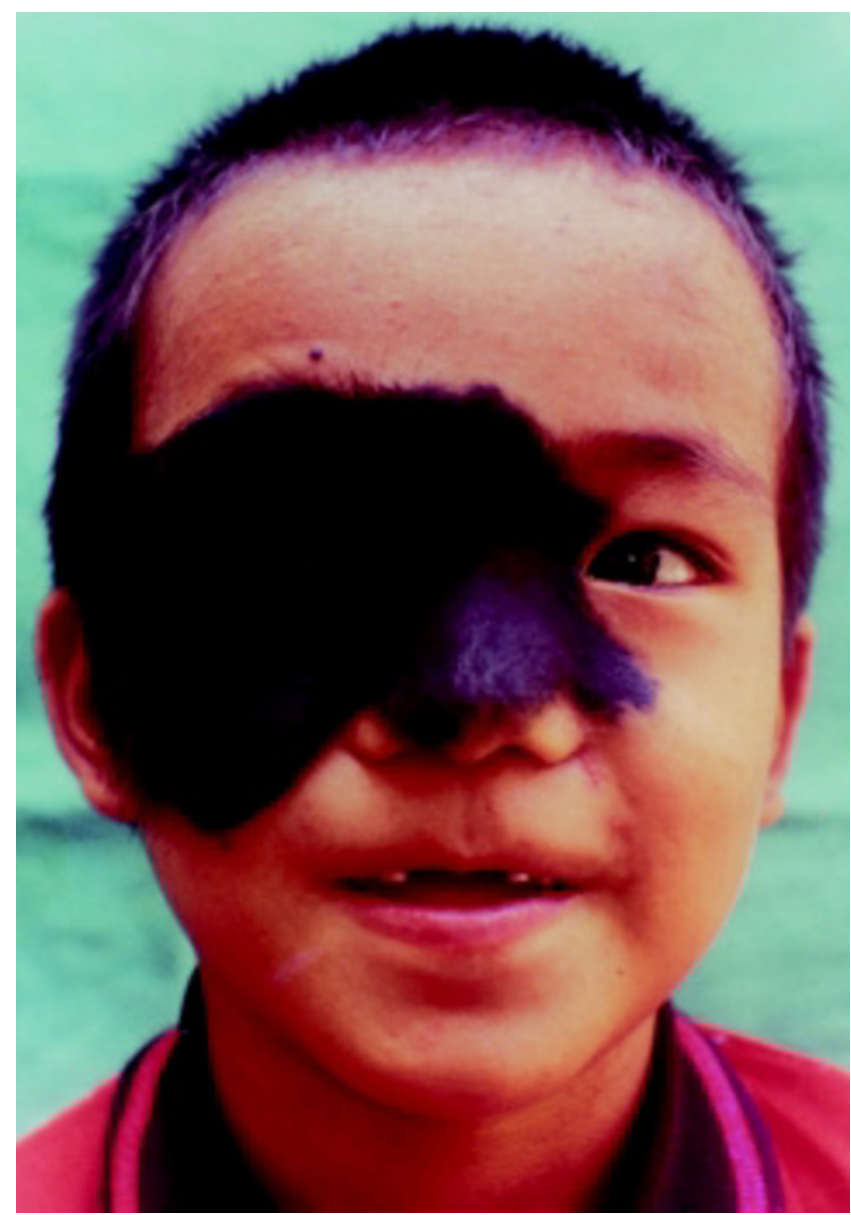

Fig. 1 : Pre-operative photograph : giant hairy pigmented nevus of face

early childhood. In one series, 10 to 20 malignant melanomas arising in giant nevi were diagnosed before 3 years of age [7]. In addition, concerns about lack of parameters to predict as to which nevi are susceptible to malignant transformation, compounded with the fact that the diagnosis gets delayed and the course in case of a malignant change is invariably fatal are reasonable [5]. A recent review [8] has concluded that an early aggressive approach to these lesions is responsible for the low risk of malignant melanoma reported in various series. Surgical excision results in the debulking of tissue at risk for the development of malignant melanoma.

Agreeing that early prophylactic excision is indicated but actually accomplishing it has posed a major management problem for most clinicians. Frustration builds up with multiple surgical procedures required and frequently poor cosmetic results. A timely co-ordinated approach to this problem has till date been hampered by the relative rarity of these lesions and the difficulty of any surgeon or service in accumulating a large enough series of patients to determine optimal therapy.

The following modalities of treatment are now well accepted by most authorities in managing giant hairy nevi of face

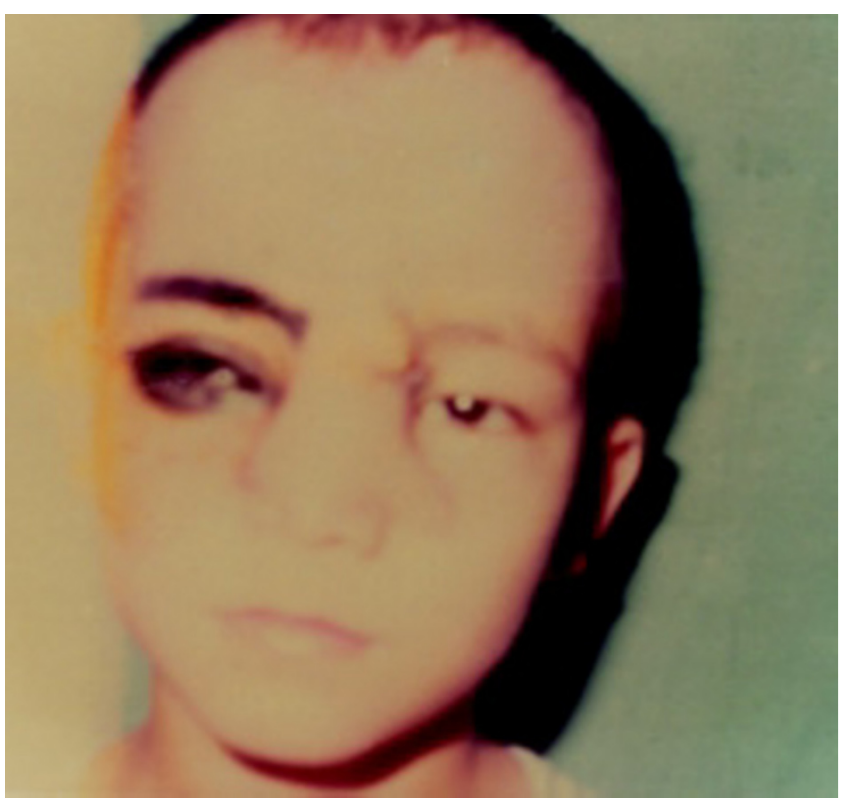

Fig. 2 : Post-operative photograph : 3 months post operative

(a) Tissue expansion is the most frequently used modality. Expansion of the forehead, neck and cheek skin facilitates an early and complete excision with minimal donor site morbidity [9].

(b) Large expanded full thickness grafts may prove invaluable in obtaining single unit, colour compatible skin coverage of the periorbital and nasal area.

(c) Expanded flaps provide with excellent tissue quality and excellent cosmetic results, while reducing the stages of surgery.

(d) Treatment can safely begin with placement of the first expanders at 3 months of age.

(e) Tissue expansion can be repeated as required for the treatment of extensive lesions.

Large and giant hairy-pigmented nevi of face present a major deformity for the child and his or her parents. It is also a major challenge for the treating plastic surgeon to plan and achieve the best cosmetic results. There is complete consensus that the percentage risk of malignancy in these cases is fairly high. Complete early prophylactic excision of these lesions is warranted and should be accomplished in infancy or early childhood. Management may require multiple surgical procedures. Tissue expansion forms the most widely used modality of treatment. Timely use of other modalities like fullthickness skin grafts and expanded flaps will decrease the number of stages of surgery while minimizing the risks of malignancy and reducing the psychological stress on the parents and the child.

\section{References}

1. Pers M. Gigantic pigmented nevi. Indications for operative treatment. Ugeskr Laeger 1963;125:613-9. 
2. Greeley PW, Middleton AG, Curtin JW. Incidence of malignancy in giant pigmented nevi. Plast Reconstr Surg 1965;36:26-37.

3. Pilney FT, Broadbent TR, Woolf RM. Giant pigmented nevi of the face: Surgical management. Plast Reconstr Surg 1967;40:46974.

4. Quaba AA, Wallace AF. The incidence of malignant melanoma (0 to 15 years of age) arising in large congenital nevocellular nevi. Plast Reconstr Surg 1986;78:174-9.

5. Dellon AL, Edelson RL, Chretien PB. Defining the malignant potential of the giant pigmented nevus. Plast Reconstr Surg 1976;57:611-7.
6. Rhodes AR, Wood WC, Sober AJ, Mihm MC. Nonepidermal origin of malignant melanoma associated with giant congenital nevocellular nevus. Plast Reconstr Surg 1981;67:782-90.

7. Kaplan EN. The risk of malignancy in large congenital nevi. Plast Reconstr Surg 1974;53:421-8.

8. Weinberg MJ, Al-Qattan M, Zuker RM, Thomson HG, Lindsay WK. Congenital giant pigmented nevi: Clinical features and risk of malignancy. Can J Plast Surg 1996;4(2):94-8.

9. Bruce S, Bauer MD, Frank A, Vicari MD. An approach to excision of congenital giant pigmented nevi in infancy and early childhood, Plast Reconstr Surg 1988;82:1012-21.

\section{Events Calendar}

\section{$5^{\text {th }}-19^{\text {th }}$ August, 2005}

HANDS-ON: 'Molecular Biology in the New Millennium'

Venue : Department of Microbiology

Molecular biology section

Armed Forces Medical College

Pune-40

\section{$0^{\text {th }}-09^{\text {th }}$ October, 2005}

Retina Update

Venue : Department of Ophthalmology

Armed Forces Medical College

Pune-40

\section{4-25 September 2005}

National Conference on Grading, Rating, Accreditation, Certification and Evaluation of Healthcare Facilities

Venue :

Department of Hospital Administration, Armed Forces Medical College,

Pune- 411040

(in collaboration with All India Institute of Medical Sciences, New Delhi)

Contact Person : Col M Dayananda, Professor \& Head

Lt Col S Basu, Associate Professor

Wg Cdr Mayank Shukla, PG Resident

Department of Hospital Administration, AFMC Pune

020-2630 6015, 020-26306046, 020-26306088

E-mail :- grace2005_afmc@yahoo.co.in 